\title{
Cheating and Feeling Honest: Committing and Punishing Analog versus Digital Academic Dishonesty Behaviors in Higher Education
}

\author{
Adi Friedman, Ina Blau, and Yoram Eshet-Alkalai \\ The Open University of Israel, Ra'anana, Israel
}

\section{adifr@openu.ac.il inabl@openu.ac.il yorames@openu.ac.il}

\section{Abstract}

This study examined the phenomenon of academic dishonesty among university students. It was based on Pavela's (1997) framework of types of academic dishonesty (cheating, plagiarism, fabrication, and facilitation) and distinguished between digital and "traditional"- analog dishonesty. The study analyzed cases of academic dishonesty offenses committed by students, as well as the reasons for academic dishonesty behaviors, and the severity of penalties for violations of academic integrity. The motivational framework for committing an act of academic dishonesty (Murdock \& Anderman, 2006) and the Self-Concept Maintenance model (Mazar, Amir, \& Ariely, 2008) were employed to analyze the reasons for students' dishonest behaviors. We analyzed 315 protocols of the Disciplinary Committee, at The Open University of Israel, from 2012-2013 that represent all of the offenses examined by the Committee during one and a half years. The findings showed that analog dishonesty was more prevalent than digital dishonesty. According to the students, the most prevalent reason for their academic dishonesty was the need to maintain a positive view of self as an honest person despite violating ethical codes. Interestingly, penalties for analog dishonesty were found to be more severe than those imposed for digital dishonesty. Surprisingly, women were penalized more severely than men, despite no significant gender differences in dishonesty types or in any other parameter explored in the study. Findings of this study shed light on the scope and roots of academic dishonesty and may assist institutions in coping effectively with this phenomenon.

Keywords: digital academic dishonesty, cheating, plagiarism, fabrication, facilitation, academic integrity in higher education, motivation for academic dishonesty, gender differences in penalties given for academic dishonesty

\section{Introduction}

(CC BY-NC 4.0) This article is licensed to you under a Creative Commons AttributionNonCommercial 4.0 International License. When you copy and redistribute this paper in full or in part, you need to provide proper attribution to it to ensure that others can later locate this work (and to ensure that others do not accuse you of plagiarism). You may (and we encourage you to) adapt, remix, transform, and build upon the material for any non-commercial purposes. This license does not permit you to use this material for commercial purposes.
In recent years the phenomenon of academic dishonesty has gained momentum among university students. Furthermore, a significant proportion of cases of academic dishonesty are digital dishonesty behaviors, which are conducted through a technological device, such as a smartphone, and an application, such as email or a social network (Stogner, Miller, \& Marcum, 2013). The broad scope of academic dishonesty is evident from several studies. For example, Cheshin (2006) found that $95 \%$ of the

\section{Editor: Janice Whatley}

An earlier, shorter version of this paper was presented at the Chais conference 2016, in Raanana, Israel, and included in Y. Eshet-Alkalai, I. Blau, A. Caspi, N. Geri, Y. Kalman, \& V. Silber-Varod (Eds.), Proceedings of the 11th Chais Conference for the Study of Innovation and Learning Technologies 2016: Learning in the Technological Era. Raanana: The Open University of Israel. 
students in Israel admitted having committed some form of academic dishonesty, some $60 \%$ had been involved in copying papers, and some $60 \%$ had been involved in copying during exams. In a study conducted in Korea, $69 \%$ of the participating students admitted that they had committed at least one of the most common forms of dishonesty - cheating, plagiarism, and facilitation (Ledesma, 2011). Similar data can be found in educational systems elsewhere in the world (Bretag, 2016).

This study focused on the phenomenon of both analog and digital academic dishonesty, aiming to analyze its most prevalent manifestations, its inhibiting and promoting factors, and the severity of penalties imposed for conducting acts of dishonesty by students.

\section{Literature Review and Frameworks}

Studies on academic dishonesty indicate that, as a rule, institutions have difficulty coping with the phenomenon because they are concerned about damaging their reputation. As a result, many institutions tend to "sweep the issue under the carpet" (Brimble, 2016; Whitley \& Keith-Spiegel, 2002).

In light of the increase in cases of violation of academic integrity in recent years, the research literature has examined the contribution of available digital technologies to academic dishonesty, and claims that the ease of conducting digital academic dishonesty encourages the phenomenon (Stogner et al., 2013). Recent research literature (e.g., Brimble, 2016; Sutherland-Smith, 2016) suggests that the digital environment seems to promote academic misconduct because of the easiness of cutting and pasting texts (plagiarism), buying/selling academic assignments and papers for re-submission (contract cheating), hiring others to write assignments and papers for students (ghost writing), and conducting online discussions that are not permitted by the institution (collusion) According to these claims, the unlimited availability of open information, and in many cases the lack of identity of the authors (such as in Wikipedia), often blur the boundaries between ethical and non-ethical behaviors and increase acts of academic dishonesty by students and even by teachers (Alroi-Stein, 2008). This claim is supported by findings from a recent rigorously conducted field experiment (Kauffman \& Young, 2015), in which the use of a plagiarism-detecting app revealed that about $80 \%$ of the participating students engaged in digital plagiarism. Moreover, the technological affordances of the writing assignment to support plagiarism (i.e., the possibility of easily copy-pasting text from internet pages) versus the special precaution taken by the researchers against plagiarism (by using jpeg format of text), impacted plagiarism far beyond the participants' writing goals which were prompted prior to the experiment (i.e., learning/mastery versus performance goals). Some studies on academic dishonesty (e.g., Jones \& Sheridan, 2015) report that sophisticated students are involved in cyber-facilitated plagiarism known as "back translation", in which students run text through language translation software in order to avoid detection of plagiarism by software. Other authors (e.g., Davies \& Howard, 2016) contend that there is no empirical evidence to corroborate the widespread fear that digital plagiarism is increasing.

The mapping of academic dishonesty in the current study is based on the conceptual framework of Pavela (1997), which relates to four types of dishonesty:

Cheating - the intentional use of study materials, information, or any kind of aid, the use of which is not allowed, including consulting with other people;

Plagiarism - the use of content written by others and presenting it without crediting the source, as if it were one's own;

Fabrication - the intentional fabrication of information, data, or references that do not actually exist;

Facilitation - intentional assistance in the academic dishonesty behavior of others 
Although it is one of the most widely accepted models today in terms of describing academic dishonesty, it is important to note that Pavela's (1997) model was developed before digital technologies became the key tools in social communication as well as in the location and storage of information. Hence a study applying it to the digital era can examine its validity today and suggest necessary modifications to it (Blau \& Eshet-Alkalai, 2014, 2015).

Motivations for conducting academic dishonesty can be analyzed from ethical, pedagogical, economic, and psychological points of view (Blau \& Eshet-Alkalai, 2016; Fishman, 2016). The findings of authors embracing the ethical perspective (e.g., Newton, 2016) have shown that students who were more confident in their understanding of plagiarism as a problematic behavior not only performed better on simple tests of referencing, but also recommended more severe penalties for conducting academic dishonesty offenses.

In the current study, we applied Murdock and Anderman's (2006) model of motivations for academic dishonesty, which analyzes academic integrity from pedagogical, economic, and psychological perspectives. The model, which is based on a meta-analysis of extensive research literature, contains three categories of motives: the student's goals, the student's evaluation of the manner in which these goals are attained, and the student's evaluation of the benefits versus the costs of conducting the act of academic dishonesty. In this model, the factors that promote dishonesty are mainly those that emphasize elements which are external to learning (e.g., focusing on the grades rather than on the development of mastery, low self-efficacy of academic performance, poor quality of teaching, perception of assessment level as too high or unfair, and the expectation that the penalty for being caught will not be severe).

This typology of the motivation for academic dishonesty was compared in our study to that of the Self-Concept Maintenance Model (Mazar, Amir, \& Ariely, 2008). From this psychological perspective, at the individual level, the key factor for committing academic dishonesty is not the benefit or the cost but rather the ability to maintain one's self-image as an honest person, despite conducting the dishonest act. On the other hand, at the group level, when other people might benefit from the dishonest act (e.g., helping friends write a seminar paper), the ethical considerations are weakened and the willingness to deceive increases (Friedman, Blau, \& Eshet, 2016). According to the Self-Concept Maintenance Model, social conventions also influence the phenomenon of dishonesty. For example, if the inappropriate behavior of one's peers is forgiven or is not addressed, it becomes a norm and thereby encourages the dishonest behavior (Ariely, 2012).

In order to improve our understanding of dishonesty in academia, this paper examined the distribution and the motivation for conducting academic dishonesty among university students.

\section{Research Questions}

The research questions are as follows:

1. Are there differences in the frequency of academic dishonesty types (according to the model of Pavela, 1997) between analog dishonesty and digital dishonesty?

2. What is the frequency of the types of motivation to be dishonest (according to the model of Murdock and Anderman, 2006)?

3. What differences are there in the severity of the actual and probationary penalties imposed for analog versus digital acts of academic dishonesty, and for the dishonest acts committed on different types of assessments (exams, seminar papers, and homework assignments)?

4. Are there gender differences in the frequency of acts of analog versus digital academic dishonesty, in different types of assessments (exams, papers, homework), and in the severity of penalties (either actual or probationary) imposed for these behaviors? Note that in contrast to 
actual penalties which are imposed immediately, probationary penalties refer to potential and usually more severe penalties that will be imposed on a student for repeating similar offenses in the future.

\section{Method}

\section{Research Population}

This study analyzed 315 protocols of the Disciplinary Committee of the Open University of Israel which deals with violations of academic integrity by its undergraduate and graduate students. Note that the retrospective analysis of the Disciplinary Committee protocols was conducted without the participation of the students who were sentenced, but rather according to the Disciplinary Committee's records alone.

The rulings are available to the public once the student's personal data and the identification of courses in which academic dishonesty behaviors were committed have been removed. The protocols contain the following information: details about the offense, the student's reasons for committing it, the presence or absence of the student at the hearing, the committee's decision, and justification of the penalty (if one has been imposed). The protocols analyzed in this study were all cases that the Disciplinary Committee dealt with during the year 2012 and the first half of 2013.

\section{Research Tools and Procedure}

The frequency of the academic dishonesty types was identified by encoding the act described in each Disciplinary Committee protocol according to Pavela's (1997) model (i.e., cheating, plagiarism, fabrication, and facilitation) and distinguishing between digital and analog academic dishonesty (Blau, Eshet-Alkalai, \& Rotem, 2014; Rotem, Blau \& Eshet-Alkalai, 2016).

The reasons for committing the offense stated in the protocols were encoded and analyzed using the model of motivation for academic dishonesty (Murdock \& Anderman, 2006): (1) extrinsic/intrinsic learning goals, (2) performance/mastery orientation, (3) low/high self-efficacy of academic performance, (4) low/high learning outcome expectations, (5) low/high perception of the chances of getting caught and punished, and (6) potential positive/negative view of self after conducting the offense. The last two codes (5 and 6), based on the model by Murdock and Anderman, were compared to the perspective offered by the model of behavioral ethics (Mazar et al., 2008), according to which the key factors in committing academic dishonesty are not cost-benefit considerations but rather the desire to maintain one's self-image as an honest person, despite conducting the dishonest act. The motivations for conducting offenses were coded independently by two raters for the entire set of protocols. In cases of disagreement, the cases were discussed until full agreement was reached.

In addition, the actual and probationary penalties imposed by the Committee were encoded (see the Appendix for details of the penalties and their degree of severity). The severity of the actual and probationary penalties was based on the scale suggested by the Disciplinary Committee to its members. The scores for the penalties were independently assessed by two raters and then discussed until that total agreement was obtained. Following that, the scores were revised by the third rater. In cases in which students were given more than one penalty, the severity was calculated as the sum of the codes for all penalties. The most severe form of penalty - permanent suspension - was coded to be significantly higher than the sum of other penalties simultaneously imposed by the Disciplinary Committee over the years. The penalty was examined on a scale from 0 - acquittal to 40-permanent suspension (for actual penalty - range: 0-40, average: 9.60, 
standard deviation: 7.713, median: 9, skewness: 1.063; for probationary penalty - range: 3-40, average: 14.37, standard deviation: 8.894, median: 13, skewness: 1.922).

\section{Findings and Discussion}

This section first analyzes types of digital and analog academic dishonesty as well as motivations of students for dishonest behavior. Following that we discuss actual and probationary penalties for conducting academic dishonesty in different types of assessments. We conclude this section by presenting gender comparisons in academic dishonesty types, motivations, and penalties for these acts.

\section{Technology and Academic Dishonesty}

The study findings indicated that $68.8 \%$ of the academic dishonesty behaviors sentenced by the Disciplinary Committee during one and a half years were analog dishonesty, while only $31.2 \%$ are digital acts of dishonesty. This prevalence of analog over digital academic dishonesty in assessments of students in academia can be explained by the fact that most of the offenses were conducted during exams which are almost exclusively analog.

As for the frequency of the academic dishonesty types according to Pavela's framework, $78 \%$ of the cases caught and sentenced by the Disciplinary Committee involved cheating. The other $17.5 \%$ were cases of plagiarism, and $4.5 \%$ were facilitating the dishonesty of other students. Surprisingly, the protocols of the Disciplinary Committee did not show a single case of fabrication, which was the most prevalent dishonesty type in a previous study among school students (Blau \& Eshet-Alkalai, 2014, 2015, 2016). These differences can be explained by the research population - university students as opposed to school students- and/or by the analysis of cases that were caught and punished by the Disciplinary Committee in the current study as opposed to the report of all of the cases of academic dishonesty in the previous study by Blau and Eshet-Alkalai (2015), including the self-report of offences that were committed by students but not detected by their teachers. An alternative explanation for this finding might be that the fabrication of data or arguments is harder to identify in the work of university students as opposed to school students.

Regarding the correlation between the technology factor and the types of dishonesty, a significant moderate to strong positive correlation was found (Cramer's $V=.39, p=.000$ ). Figure 1 presents the prevalence of each type of academic dishonesty separately for digital and analog offences. It shows that the majority of cases of cheating took place in an analog environment, while facilitation and plagiarism were more prevalent in a digital setting. These findings are consistent with the study among school students by Blau and Eshet-Alkalai $(2014,2015)$, in which plagiarism and facilitation were more prevalent and were perceived as more legitimate in a digital environment.

Regarding analog and digital dishonesty according to the type of assessment, most acts of dishonesty were discovered during exams, which usually do not involve the use of any technology.

Nevertheless, the protocols analyzed in this study included $46(19.6 \%)$ examples of digital dishonesty during an exam - mainly via the use of smartphones. 


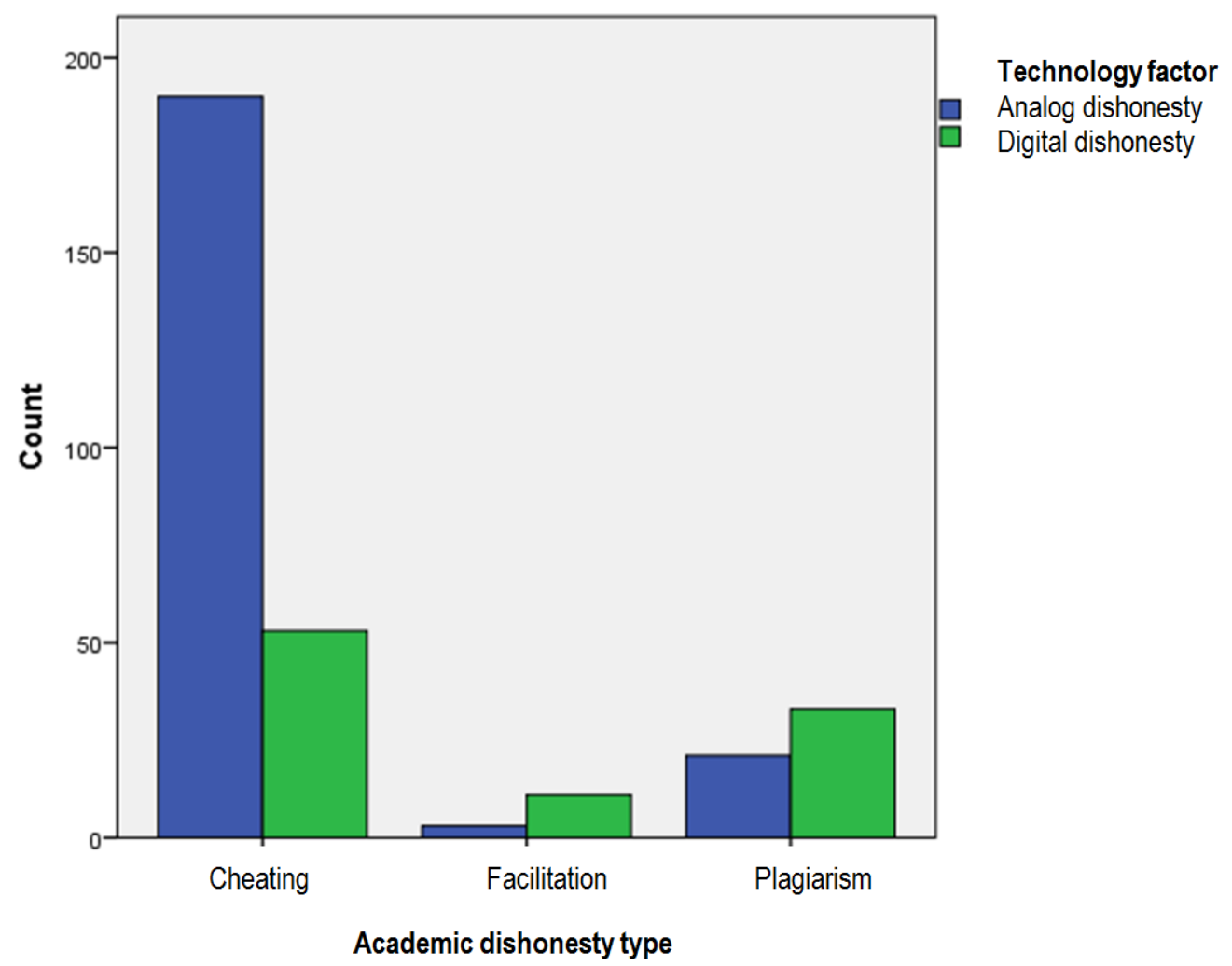

Figure 1: Types of analog and digital academic dishonesty behaviors

\section{Motivations for Conducting Academic Dishonesty}

Table 1 presents frequencies of the motivations for academic dishonesty stated by students and coded based on the model of motivations for academic dishonesty (Murdock \& Anderman, 2006).

Surprisingly, findings in Table 1 indicate that most students who were caught (almost $60 \%$ ) claimed that they had acted innocently, in the belief that what they did was legitimate. The study findings support the Self-Concept Maintenance Model (Mazar et al., 2008) and indicate that most of the motives for dishonesty reported by the students derive from a desire to preserve their selfimage as honest people. Thus, the findings suggest that the manner of coping with academic dishonesty requires a different approach to the traditional one of imposing penalties. An example of how to prevent the phenomenon is by blurring the uncertainty students have regarding the ethical dissonance involved in committing the offense. In other words, if the student knows that an act would certainly violate their academic integrity and by committing the offense he/she becomes a dishonest person, there is a lower chance that he/she might commit it (Shalvi, Gino, Barkan, \& Ayal, 2015). 
Table 1 - Frequency of motivation for dishonesty based on Murdock and Anderman (2006)

\begin{tabular}{|l|c|l|}
\hline $\begin{array}{l}\text { Motivation for academic } \\
\text { dishonesty }\end{array}$ & Frequency & $\begin{array}{l}\text { Example from the protocols of the } \\
\text { Disciplinary Committee }\end{array}$ \\
\hline $\begin{array}{l}\text { Extrinsic rather than intrinsic } \\
\text { goals }\end{array}$ & $0.6 \%$ & $\begin{array}{l}\text { A student who submitted a copied home- } \\
\text { work assignment claimed that she did so } \\
\text { because of pressure and financial distress }\end{array}$ \\
\hline $\begin{array}{l}\text { High performance orientation } \\
\text { rather than mastery orientation }\end{array}$ & $10.8 \%$ & $\begin{array}{l}\text { A student who submitted a copied seminar } \\
\text { paper claimed that she did so because of } \\
\text { time constraints and the pressure to finish } \\
\text { her degree. }\end{array}$ \\
\hline $\begin{array}{l}\text { Low self-efficacy of academic } \\
\text { performance }\end{array}$ & $10.5 \%$ & $\begin{array}{l}\text { A student who copied notes during an ex- } \\
\text { am said she did so because she had diffi- } \\
\text { culty expressing herself in writing. }\end{array}$ \\
\hline $\begin{array}{l}\text { Low learning outcomes expec- } \\
\text { tations }\end{array}$ & $4.1 \%$ & $\begin{array}{l}\text { A student who copied on an exam said that } \\
\text { because of family problems he had been } \\
\text { unable to study properly for the exam. }\end{array}$ \\
\hline $\begin{array}{l}\text { Perception of the chances of } \\
\text { getting caught and punished as } \\
\text { low }\end{array}$ & $10.2 \%$ & $\begin{array}{l}\text { A student caught with a mobile phone dur- } \\
\text { ing an exam claimed that he committed the } \\
\text { offense knowing it was forbidden, but he } \\
\text { didn't have anywhere to store the phone } \\
\text { and didn't think someone will notice it. }\end{array}$ \\
\hline $\begin{array}{l}\text { Positive view of self ("inno- } \\
\text { cence" claim) - self- percep- } \\
\text { tion as an honest person de- } \\
\text { spite the act of dishonesty }\end{array}$ & $59.6 \%$ & $\begin{array}{l}\text { A student who copied on an exam from her } \\
\text { own notes said she did so because she did } \\
\text { not know it was forbidden. }\end{array}$ \\
\hline
\end{tabular}

\section{Penalties}

Since a statistically significant difference was found between the penalties imposed in 2012 and in the first half of 2013, the data could not be combined in a single sample and this section is based on the 257 penalties imposed by the Disciplinary Committee during 2012 alone. An independent sample $t$-test was conducted to compare the severity of the penalties imposed for digital dishonesty as opposed to analog dishonesty. Table 2 presents the descriptive statistics and the analysis of variance for the severity of the actual and probationary penalties imposed on students conducting analog and digital offenses.

Table 2 - Severity of penalties imposed on students for analog or digital dishonesty in 2012

\begin{tabular}{|l|l|l|l|l|}
\hline Penalty type & $\begin{array}{l}\text { Dishonesty } \\
\text { type }\end{array}$ & Average & SD & $\boldsymbol{t}$ \\
\hline Actual & Analog & 11.77 & 7.889 & \multirow{2}{*}{$t(256)=3.886, p=.000$} \\
\cline { 2 - 5 } & Digital & 7.74 & 7.418 & \\
\hline Probationary & Analog & 16.46 & 9.493 & \multirow{2}{*}{$t(208)=1.598, p=.112$} \\
\cline { 2 - 5 } & Digital & 14.42 & 6.434 & \\
\hline
\end{tabular}


The results presented in Table 2 indicate that in 2012 the actual penalties for analog dishonesty were significantly more severe than those for digital dishonesty. It seems that digital dishonesty is perceived as less severe an offense than analog dishonesty - probably because the information on the internet is seen by many as the public domain and thus is not subject to copyright protection. This finding is consistent with a previous study which found that the accessibility of open online information augments academic dishonesty (Robinson-Zanartu, et al., 2005).

In order to examine the effect of the dishonesty type on the severity of the penalty, two univariate ANOVA tests were conducted: one for the actual penalty and the other for the probationary penalty. Table 3 shows the descriptive statistics of the tests.

Table 3 - Effect of academic dishonesty type on the severity of the penalty

\begin{tabular}{|l|l|l|l|}
\hline \multicolumn{1}{|l|}{ Penalty } & $\begin{array}{l}\text { Cheating Aver- } \\
\text { age (SD) }\end{array}$ & $\begin{array}{l}\text { Plagiarism } \\
\text { Average (SD) }\end{array}$ & $\begin{array}{l}\text { Facilitation } \\
\text { Average (SD) }\end{array}$ \\
\hline Actual & $10.28(7.268)$ & $12.15(9.121)$ & $7.33(12.353)$ \\
\hline Probationary & $14.78(7.409)$ & $19.30(11.044)$ & $21.80(16.739)$ \\
\hline
\end{tabular}

Analysis of the variance showed no statistically significant effect of the academic dishonesty type on the severity of the actual penalties $\left(F(2,255)=2.073, p=.128, \eta^{2}=.016\right)$. In other words, the findings do not indicate differences in the severity of actual penalties between the types of dishonesty the students committed. In contrast, a significant effect of the dishonesty type on the severity of the probationary penalties was found $\left(F(2,207)=5.850, p=.03, \eta^{2}=.053\right)$. Least Significant Difference (LSD) pairwise comparisons showed that the probationary penalties imposed for plagiarism were significantly more severe than those imposed for cheating $(p=.003)$, and the probationary penalties imposed for facilitation were more severe than those imposed for cheating at a marginally significant level ( $p=.07)$. No significant differences were found between probationary penalties for plagiarism compared to facilitation $(p=.535)$.

In addition, two univariate ANOVA tests were conducted to examine the effect of the assessment type on the severity of the actual and probationary penalty imposed on students for digital or ana$\log$ dishonesty. Table 4 presents the descriptive statistics of these tests.

Table 4 - Effect of the assessment type on the severity of the penalty for AD

\begin{tabular}{|l|l|l|l|}
\hline Penalty & $\begin{array}{l}\text { Exam } \\
\text { Average (SD) }\end{array}$ & $\begin{array}{l}\text { Seminar Paper } \\
\text { Average (SD) }\end{array}$ & $\begin{array}{l}\text { Homework as- } \\
\text { signment } \\
\text { Average (SD) }\end{array}$ \\
\hline Actual & $9.97(7.510)$ & $16.67(10.217)$ & $10.29(8.369)$ \\
\hline Probationary & $14.44(7.020)$ & $31.36(12.220)$ & $15.41(7.989)$ \\
\hline
\end{tabular}

The analysis of variance indicated a significant difference in the severity of the actual penalties between the different types of assessment $\left(F(257,2)=5.090, p=.007 \eta^{2}=.038\right)$. LSD pair comparisons showed that the penalties for dishonesty in writing a seminar paper were more severe than those imposed for dishonesty in an exam $(p=.002)$ and for writing a homework assignment $(p=.006)$. Surprisingly, no difference was found between the penalties for dishonesty in an exam and a homework assignment $(p=.779)$. The possible explanation is that a seminar paper is usually written at the final stage of degree studies, is supposed to be the fruit of an extended period of work, and its weight in the GPA is relatively high. Therefore it might be considered by the Disci- 
plinary Committee as more severe dishonesty than one conducted in an exam, which may be a preliminary stage in degree studies, or a homework assignment, the weight of which in the course grade is not very high.

Regarding the severity of probationary penalties, the findings of the test indicate a significant difference and a large effect size of the severity of the penalty between the different assessment types $\left(F(209,2)=31.704, p=.000, \eta^{2}=.238\right)$. LSD pair comparisons showed that the probationary penalties for dishonesty in writing a seminar paper are more severe than those for dishonesty in an exam and for a homework assignment ( $p$ 's=.000). Thus it seems that the Disciplinary Committee imposes severe penalties - actual and probationary alike - for dishonesty in writing seminar papers. Surprisingly, no statistically significant difference was found between the probationary penalties for dishonesty in an exam and in a homework assignment $(p=.477)$.

\section{Gender Differences}

An independent sample $t$-test was conducted to examine the differences in the severity of the penalties as a function of students' gender. Table 5 presents the descriptive statistics and analysis of variance of the severity of the actual and probationary penalties according to gender.

Table 5 - Severity of the actual and probationary penalties by gender

\begin{tabular}{|l|l|l|l|l|}
\hline Penalty type & Gender & Average & SD & $\boldsymbol{t}$ \\
\hline Actual & Male & 8.44 & 6.841 & \multirow{2}{*}{$t(312)=2.370, p=.018$} \\
\cline { 2 - 4 } & Female & 10.51 & 8.239 & \\
\hline Probationary & Male & 14.50 & 9.123 & \multirow{2}{*}{$t(243)=.192, p=.848$} \\
\cline { 2 - 4 } & Female & 14.28 & 8.744 & \\
\hline
\end{tabular}

Table 5 shows that, surprisingly, the actual penalties imposed on female students are significantly harsher than those imposed on male students. No significant gender differences were found for the probationary penalties. This result contradicts the findings of studies on the punishments sentenced among men as opposed to women in the courts. For example, a study that examined statistical data in the courts of the large states in the USA between 1990 and 1996 found that women were less severely punished than men (Steffensmeier \& Demuth, 2006).

In an attempt to explain the gender differences identified in the severity of actual penalties, we examined whether gender differences are present in other parameters described in the protocols. No significant gender difference was found in analog dishonesty as opposed to digital dishonesty $\left(\chi_{(1)}^{2}=.021, p=.886\right)$. Also, no significant difference was found between the genders in the type of assessment $\left(\chi_{(2)}^{2}=1.239, p=.538\right)$. Hence our findings do not show gender differences between analog and digital dishonesty and the types of assessment (exam, seminar paper, and homework assignment). Moreover, it should be noted that no gender differences were found for the parameters of the appearance of a student before the committee, the cooperation of the student when caught in the dishonesty act, or the parameter of whether the student admitted guilt and expressed remorse. Thus, the disturbing gender differences in the severity of penalty imposed the Disciplinary Committee cannot be explained by the different academic dishonesty behavior of female students or their unwillingness to cooperate after being caught. This finding might be related to the fact that during the period analyzed in this study the Committee only consisted of men and we recommend that academic institutions adopt more gender-balanced compositions of Disciplinary Committees. 


\section{Conclusion and Implications}

This study explored the phenomenon of analog and digital academic dishonesty, aiming to analyze its most common manifestations, the factors that lead students to commit it, the severity of penalties imposed for it by the Disciplinary Committee and gender differences in these penalties. Concerning different types of offenses, the findings indicate that Pavela's (1997) model relating to four types of academic dishonesty requires expansion in order to explain the phenomenon in the digital era. Faculty should pay additional attention to the fabrication of data or arguments that were not identified in the protocols of the Disciplinary Committee analyzed in this study, although they were very common in a previous study among school students (Blau \& Eshet-Alkalai, 2014, 2015). Regarding motivation for dishonesty, the findings support the Self-Concept Maintenance model (Mazar et al., 2008), showing students conduct dishonesty when they are still able to preserve themselves as honest people, despite their misbehavior. This finding might contribute to the development of effective policies and strategies for coping with academic dishonesty. Findings related to the penalties showed that penalties for analog dishonesty were more severe than those imposed for digital dishonesty. We recommend that Disciplinary Committee members should be aware of possible biases of perceiving digital dishonesty offenses as less severe than analog dishonesty offenses. Surprisingly, women were consistently penalized more severely than men, despite no significant gender differences in dishonesty types or in any other parameter explored in the study.

\section{Limitations and Future Work}

It should be taken into consideration that, although this study analyzes actual students' academic dishonesty in a large university during a period of a year and a half, it was conducted in one academic institution. Future studies might compare the data between different Israeli academic institutions and between universities in different countries. The method applied in the study of analyzing Disciplinary Committee rulings in an academic institution is an innovative research approach, and we hope that future studies will embrace it in order to shed light on the phenomenon and ways to prevent it.

\section{References}

Alroi-Stein, O. (2008). Cheapening of academic values in the age of the information and communication revolution. Al Hagova, Academic Track at the College of Management, 7, 56-57. [in Hebrew].

Ariely, D. (2012). The (honest) truth about dishonesty: How we lie to everyone - especially to ourselves. HarperCollins Publishers.

Blau, I., \& Eshet-Alkalai, Y. (2014). School students' perception of academic dishonesty with and without digital tools: Not acceptable, but common. Paper presented at the International Conference on Advanced Education and Management - ICAEM2014. Beijing, China.

Blau, I., \& Eshet-Alkalai, Y. (2015). Cheating through digital technologies from the perspective of Israeli students, teachers and parents - Patterns and coping strategies. Research report for the Chief Scientist Foundation, Ministry of Education. [in Hebrew]. Retrieved from http://ecat.education.gov.il/Attachment/DownloadFile?downloadId=5397

Blau, I., \& Eshet-Alkalai, Y. (2016). How digital technologies affect academic dishonesty behavior of school students? In Proceedings of the International Conference on Internet Studies - NETs2016. Osaka, Japan.

Blau, I., Eshet-Alkalai, Y., \& Rotem, I. (2014). Cheating and e-cheating: A qualitative investigation of expanding an academic dishonesty framework into digital learning settings. In Proceedings of the 8th International Technology, Education and Development Conference - INTED2014 (p. 5002). Valencia, Spain. 
Bretag, T. (Ed.), (2016). Handbook of academic integrity (pp. 7-21). SpringerNature: Springer ScienceBusiness Media Singapore.

Brimble, M. (2016). Why students cheat: An exploration of the motivators of student academic dishonesty in Higher Education. In T. Bretag (Ed.), Handbook of academic integrity (pp. 365-382). SpringerNature: Springer Science-Business Media Singapore.

Cheshin, Y. (2006). Academic integrity in institutions of higher education in Israel. Al Hagova, Academic Track at the College of Management, 5, 17-19. [in Hebrew].

Davies, L. J. P., \& Howard, R. M. (2016). Plagiarism and the Internet: Fears, facts, and pedagogies. In T. Bretag (Ed.), Handbook of academic integrity (pp. 591-606). SpringerNature: Springer ScienceBusiness Media Singapore.

Fishman, T. (2016). Academic integrity as an educational concept, concern, and movement in US institutions of higher learning. In T. Bretag (Ed.), Handbook of academic integrity (pp. 7-21). SpringerNature: Springer Science-Business Media Singapore.

Friedman, A., Blau, I., \& Eshet-Alkalai, Y. (2016). How and why students cheat? The role of technology in academic dishonesty and the penalties for conducting academic dishonesty. In Proceedings of the 8th annual International Conference on Education and New Learning Technologies-EDULEARN2016, Barcelona, Spain.

Jones, M., \& Sheridan, L. (2015). Back translation: An emerging sophisticated cyber strategy to subvert advances in 'digital age' plagiarism detection and prevention. Assessment \& Evaluation in Higher Education, 40(5), 712-724.

Kauffman, Y., \& Young, M. F. (2015). Digital plagiarism: An experimental study of the effect of instructional goals and copy-and-paste affordance. Computers \& Education, 83, 44-56.

Ledesma, R. G. (2011). Academic dishonesty among undergraduate students in a Korean university. Research in World Economy, 2(2), 25-35.

Mazar, N., Amir, O., \& Ariely, D. (2008). The dishonesty of honest people: A theory of self-concept maintenance. Journal of Marketing Research, 45(6), 633-644.

Murdock, T. B., \& Anderman, E. M. (2006). Motivational perspectives on student cheating: Toward an integrated model of academic dishonesty. Educational Psychologist, 41(3), 129-145.

Newton, P. (2016). Academic integrity: A quantitative study of confidence and understanding in students at the start of their higher education. Assessment \& Evaluation in Higher Education, 41(3), 482-497.

Pavela, G. (1997). Applying the power of association on campus: A model code of academic integrity. Journal of Business Ethics, 16(1), 97-118.

Robinson-Zañartu, C., Peña, E. D., Cook-Morales, V., Peña, A. M., Afshani, R., \& Nguyen, L. (2005). Academic crime and punishment: Faculty members' perception of and responses to plagiarism. School Psychology Quarterly 20(3), 318-337.

Rotem, I., Blau, I., \& Eshet-Alkalai, Y. (2016). Academic dishonesty in the digital era: Perceptions and coping strategies of school teachers and parents. In Proceedings of the Global Conference on Learning and Technology - Global Learn 2016. Limerick, Ireland.

Shalvi, S., Gino, F., Barkan, R., \& Ayal, S. (2015). Self-serving justifications: Doing wrong and feeling moral. Current Direction in Psychological Science, 24(2), 125-130.

Steffensmeier, D., \& Semuth, S. (2006). Does gender modify the effects of race-ethnicity on criminal sanctioning? Sentences for male and female white, black, and Hispanic defendants. Journal of Quantitative Criminology, 22, 241-261.

Stogner, J. M., Miller, B. L., \& Marcum, C. D. (2013). Learning to e-cheat: A criminological test of Internet facilitated academic cheating. Journal of Criminal Justice Education 24(2), 175-199. 
Sutherland-Smith, W. (2016). Authorship, ownership, and plagiarism in the Digital Age. In T. Bretag

(Ed.), Handbook of academic integrity (pp. 575-589). SpringerNature: Springer Science-Business Media Singapore.

Whitley, B. E., \& Keith-Speigel, P. (2002). Academic dishonesty: An educator's guide. Mahwah, NJ: Lawrence Erlbaum Associates, Publishers.

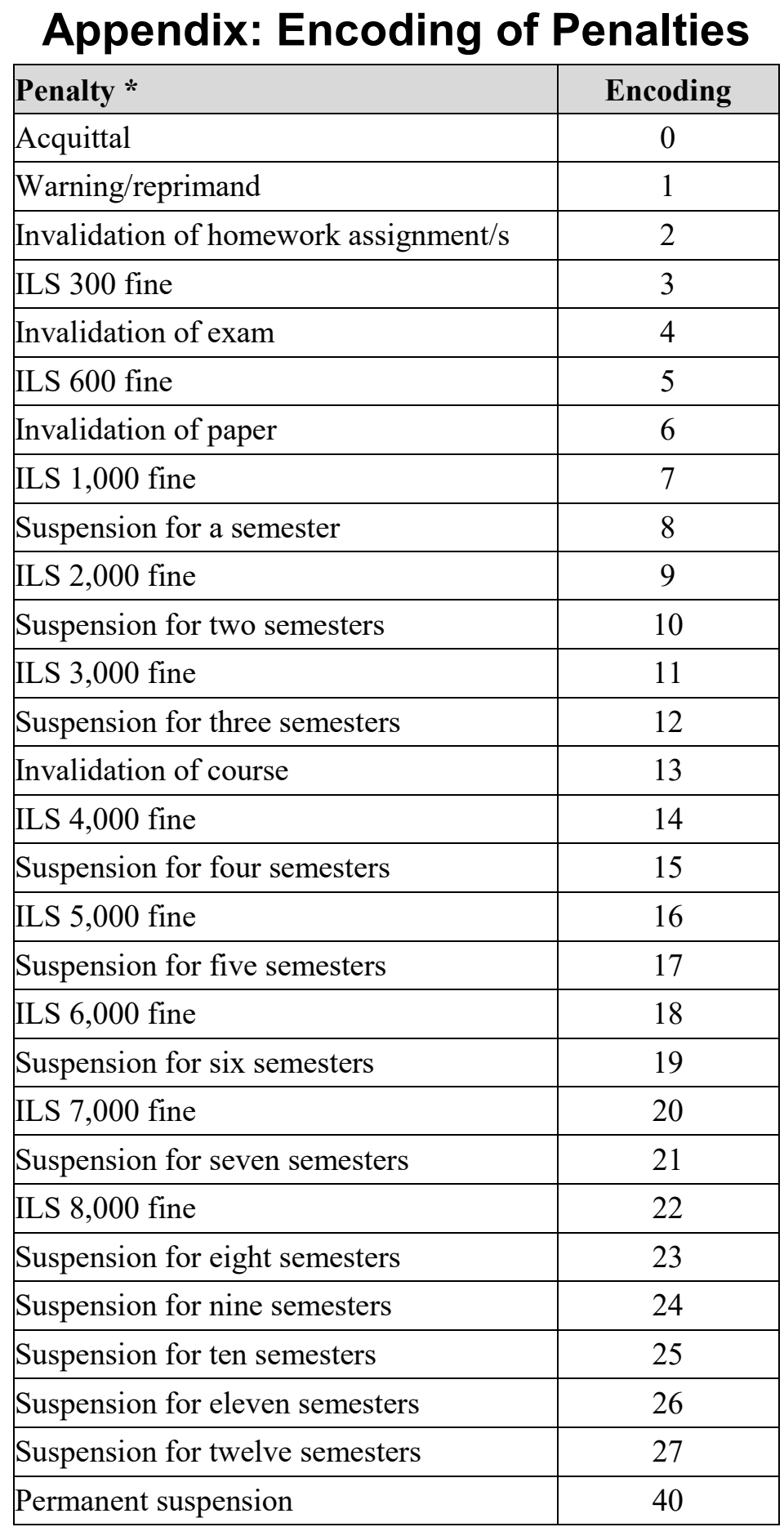

*Note: If students were given more than one penalty, the severity was calculated as the sum of the codes for all penalties. 


\section{Biographies}

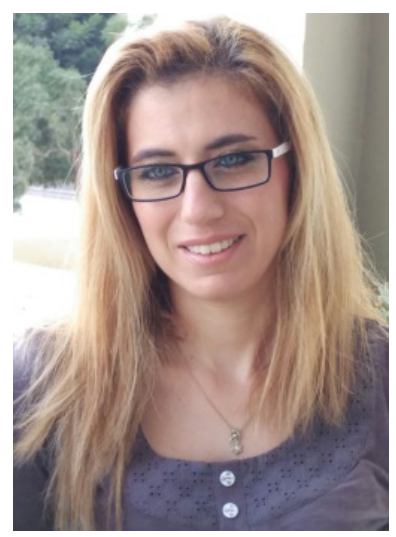

Adi Friedman is a specialist in facilitating implementation and usage of educational technologies by faculty and students at the Open University of Israel. She is currently finishing her M.A. Thesis in Education, at the Graduate Program of Learning Technologies and Learning Systems, Department of Education and Psychology, the OUI. Her main research interest is preventing and coping with the phenomenon of academic dishonesty in academia.

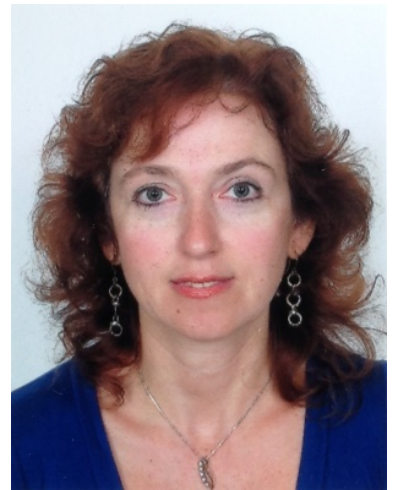

Ina Blau is a Senior Lecturer in the Department of Education and Psychology, The Open University of Israel. She holds a PhD. in ELearning and Cyber-Psychology. In 2011-2014 she was a lecturer in the Department of Information \& Knowledge Management, Graduate School of Management, University of Haifa, and in 2015 was a Visiting Scholar in the National Institute of Education (NIE) and Learning Sciences Lab, Nanyang Technological University (NTU), Singapore. Dr. Blau has diverse experience in teaching, educational management, and teacher professional development related to technology-enhanced teaching and e-learning. She is a Member of the Digital Learning committee, the Israeli Council for Higher Education. Her research interests and publications focus on social aspects of e-communication and e-leadership; integration of innovative technologies in K-12, academia, and organizations; mobile learning and interaction; digital literacy skills; the effect of "productive failure" experience on the development of creativity; psychological ownership in e-collaboration; and online privacy in social networking. She led large-scale research projects which were supported by research grants from the Israeli Ministry of Education and focused on the phenomenon of digital cheating and plagiarism from the perspective of Israeli pupils, teachers, and parents, and on processes and outcomes of one-to-one computing in schools.

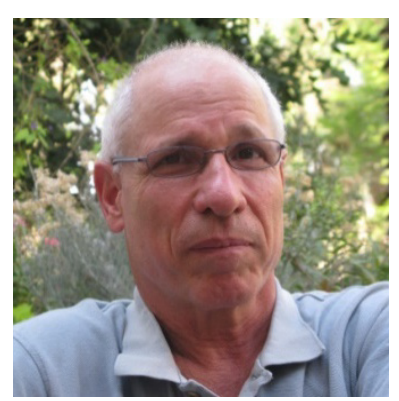

Yoram Eshet-Alkalai is a Professor at the Open University of Israel, Department of Education \& Psychology, and the Head of the M.A. Program in Learning Technologies \& Learning Systems. His major research and publications focus on digital literacy, digital reading, on human-computer interaction, and on the cognitive aspects of working with digital technologies. He studies the effect of technologies on a wide range of subjects, such as academic dishonesty, gaming, and friendship. Prof. Eshet-Alkalai has a diverse academic and professional background, including a B.A in Archeology, an M.Sc. in Geology, and a $\mathrm{PhD}$ in Earth \& Environmental Sciences. For over a decade, he worked as a chief scientist in a computer company, designing and developing computer-based learning environments for the education systems in Israel and the USA. Prof. Eshet-Alkalai was also the Head of the Instructional Design Program at Tel Hai Academic College, and for 15 years served as a senior researcher at the Geological Survey of Israel. He is also the founder and formerly the Head of the Research Center for Innovation in Learning Technologies, The Open University of Israel. 